\title{
Preliminary Report of a Drug Trial Conducted at Leprosy Relief Rural Centre, Chettipatty, South India
}

\author{
E. VOMSTEIN \\ Leprosy Relief Rural Centre, Chettipatty P.O., South India
}

\begin{abstract}
The drug combination (rifampicin + Isoprodian) therapy continues for 7 cases, it has been stopped for 19 cases-out of which 10 cases receive dapsone treatment ranging from 25 to $400 \mathrm{mg} /$ week, the other 9 cases are without DDS subjected to further observation and follow-up.

All, but 2 cases could again resume work which for some of them had not been possible for years gone by.

The experience gained till now with the drug combination therapy rifampicin + Isoprodian allows us to state that it no doubt means a noteworthy progress. This is especially so in those $\mathrm{L}$ and BL cases who never could tolerate and constantly reacted adversely to all the anti-leprosy drugs that are commonly in use.

These patients hitherto constitute an insurmountable medical and social problem.
\end{abstract}

On 22 May, 1973, a trial was started with the combination of rifampicin and Isoprodian which was introduced by Professor Freerksen for leprosy therapy. Thirty-two patients were selected-29 males and 3 females. These patients were admitted to our hospital for a few weeks before and after commencement of the drug trial to allow close clinical observation and check-up. After being discharged, they reported every 2 weeks for treatment and examination.
Type
L, 29 cases
BL, 2 cases
TM, 1 case

\begin{tabular}{|c|c|c|c|c|}
\hline \multicolumn{5}{|c|}{ Ranges from 15 to 60 years } \\
\hline Below 15 years & 1 case & male & & Type L \\
\hline 20 to 30 years & 15 cases & 13 males & 2 females & Type L \\
\hline 31 to 40 years & 9 cases & 8 males & $1 \mathrm{female}$ & Type L \\
\hline 41 to 50 years & 5 cases & 5 males & & Type: $2 \mathrm{~L}, 2 \mathrm{BL}, 1 \mathrm{TM}$ \\
\hline 51 to 60 years & 2 cases & 2 males & & Type L \\
\hline
\end{tabular}

Duration of Disease

5 to 20 years 


\section{Groups}

The cases were divided into 3 groups:

Group 1: 4 cases-2 BL and 2 L type.

No specific treatment had been taken previously (i.e. dapsone or any other anti-leprosy treatment). These patients reported to us only a short time previously and were continuously in a reactional state.

\section{Group 2: 12 cases-11 L and 1 TM type.}

Treated with a single anti-leprosy drug previously (e.g. dapsone or sulphetrone) with doubtful and unsatisfactory results. With the exception of the TM case, all the others had suffered from chronic reaction with repeated ENL.

Group 3: 16 cases-L type.

No specific treatment was tolerated (e.g. dapsone orally, sulphetrone parenterally, thiambutosine, thiosemicarbazone, Stibenol-Fantorin). In all these patients the disease was long standing with chronic reaction, and most of them suffered from severe intermittent exacerbations and widespread ulcerations.

\section{Nerves}

Twenty-three cases of groups 2 and 3 presented nerve involvement. Two cases with single nerve thickened, but not tender. Fourteen cases with multiple nerves thickened, but not tender. Seven cases with multiple nerves thickened and tender (active neuritis).

It was not possible to stabilize the condition of the cases in group 3, not even to a minimum tolerable degree. Two of these cases were steroid dependent, 2 cases depended on steroid cum thalidomide and 2 cases were thalidomide dependent.

\section{Withdrawal}

Three cases were withdrawn ( 2 males and 1 female) from the drug trial after 2 weeks and 4 months respectively because of severe reaction.

Apart from the pathological changes that pertain to Myco. leprae in these advanced and chronic reactional cases, no other pathological findings were evident on preliminary examination.

\section{Dosage}

The dosage schedule was as follows:

\begin{tabular}{ccc}
\hline $\begin{array}{c}\text { Body weight } \\
(\mathrm{kg})\end{array}$ & $\begin{array}{c}\text { Isoprodian } \\
\text { tablets }\end{array}$ & $\begin{array}{c}\text { Rifampicin } \\
\text { (mg) }\end{array}$ \\
\hline 16 & 1 & 300 \\
17 to 33 & 2 & 300 \\
34 to 49 & 3 & 600 \\
50 to 66 & 4 & 600 \\
\hline
\end{tabular}


The drug combination was administered orally after breakfast 6 days in the week. During the course of the first 6 months the dosage was reduced if the patient had any side-effects such as nausea or vomiting, and increased to the usual dosage later, thus the maintenance dose was reached and continued till the end of treatment.

\section{Role of Other Drugs}

\section{Thalidomide}

(1) Initially, together with the new drug combination, a short course of thalidomide ( $400 \mathrm{mg}$ twice a day which was gradually tapered off) was given to 6 cases ( $5 \mathrm{~L}$ and $1 \mathrm{BL}$ type) in order to control reaction. They were satisfactorily stabilized thereafter and did not require further use of thalidomide.

(2) Twenty cases ( $1 \mathrm{BL}, 18 \mathrm{~L}$ and $1 \mathrm{TM}$ type) received short courses of thalidomide, not more than $200 \mathrm{mg} / \mathrm{day}$, which was gradually reduced and then withdrawn after 6 to 7 days to control mild reactions, neuritis and ENL.

(3) Two cases (L type) remain thalidomide dependent, with a maintenance dose of $100 \mathrm{mg} /$ day and $50 \mathrm{mg} /$ day respectively.

\section{Prednisolone}

One female L case was given prednisolone instead of thalidomide. None of the patients are dependent on steroids any longer.

Apart from occasional gastric discomfort with vomiting in 2 cases, no pathological symptoms and changes were observed or reported which could undoubtably be interpreted as sequelae of the drug combination.

A few patients suffered from anorexia with sudden loss of body weight after 11 to 12 months of treatment. Af ter withdrawal there was quick recovery.

\section{Results}

There was especially marked improvement in the clinical condition in all the cases during the first 3 months. It is understood that we have to a large extent to rely on the visual evidence only. Infiltrations diminished or subsided, skin lesions flattened, became less erythematous, texture and pigmentation of the skin regained normal appearance in many cases. Ulcerations healed within a relatively short time. Neural involvement was negligible at the end of treatment.

In 1 patient, admitted in severe condition with the integument of the extremities destroyed by ulceration, and ulcers widely scattered all over the trunk (duration and former treatment not known to us); after treatment with the new drug combination the ulcerations healed up. At present this patient is on dapsone $100 \mathrm{mg} /$ week, but he is thalidomide dependent.

\section{Special Observations}

A peculiar finding observed during the course of the drug trial was partial new hair growth on eyebrows, eye-lashes, forearms, lower limbs, upper lips, chin, chest and over the patches on the legs and elbows. One patient developed a pleural empyema (right side) 1 month after the drug combination was stopped. The cause could not be definitely diagnosed. The effusion was sanguinous-purulent. Surgical 
treatment-rib resection with drainage was performed. Despite the initially toxic condition there occurred no reactivation of Myco. leprae and skin smears on this patient were found to be negative after 3 months of the drug trial.

Two patients who suffered from severe attacks of malaria of mixed type ( $P$. vivax and $P$. falciparum) did not suffer a relapse of Myco. leprae. This is remarkable because from experience we know that intercurrent diseases invariably used to provoke exacerbation, with mild to very severe reactions in patients of this kind.

\section{Surgery}

In 3 cases surgery was performed (hand, foot and gynecomastia) without any complications and with excellent results.

\section{Laboratory Findings}

All the patients had monthly examinations of urine, blood and stool. Skin smears were also done monthly. Skin biopsies of $4 \mathrm{~L}$ cases -2 males and 2 females-were taken and sent to Borstel for examination, as follows:

\begin{tabular}{ccllr}
\hline Patient No. & Type & Sex & \multicolumn{2}{c}{ Skin Biopsy No. } \\
\hline 13 & L & male & & $10 / 74$ \\
23 & L & female & $6 / 74$, & $25 / 74$ \\
24 & L & female & $7 / 74$, & $14 / 74$ \\
30 & L & male & & $8 / 74$ \\
\hline
\end{tabular}

Corresponding with the clinical findings, the $\mathrm{BI}$ in most of the cases showed marked improvement after 3 months. Six of the 8 patients who became negative were so already after 3 months.

All the patients of the negative group have remained stable, despite intercurrent occurrence of other diseases like malaria, pleural empyema, etc.

Patient No. 29 of OB (occasional bacilli) group still requires short courses of thalidomide now and again. He is on dapsone medication now.

Of the 0.16 group in the BI only 1 case is unstable, patient No. 1 . This patient is thalidomide dependent. It cannot be ruled out that he was irregular in taking the medicine during the time when he was not hospitalized.

Patient No. 15. Thalidomide dependent (see formerly mentioned history).

Patient No. 5. Very unreliable. Probably he has not taken his medication regularly.

Patient No. 25 and No. 17. Very unstable, irregular attendance.

\section{Short Histories of Four Patients}

Patient No. 23

Name: B., Age: about 34 years, female, Type L. Skin biopsy Nos 6/74 and $25 / 74$.

On treatment with us since January, 1968. Nodular lepromatous in chronic 
DRUG TRIAL, CHETTIPATTY, SOUTH INDIA

TABLE 1

Bacteriological and Granular Index

\begin{tabular}{|c|c|c|c|c|c|c|c|c|}
\hline \multirow{2}{*}{$\begin{array}{c}\text { Patient } \\
\text { No. }\end{array}$} & \multirow{2}{*}{ Sex } & \multirow{2}{*}{ Type } & \multicolumn{2}{|c|}{ Onset } & \multicolumn{2}{|c|}{ After 3 months } & \multicolumn{2}{|c|}{ After 1 year } \\
\hline & & & $\mathrm{BI}^{a}$ & $\mathrm{GI}^{b}$ & $\mathrm{BI}^{a}$ & $\mathrm{GI}^{b}$ & $\mathrm{BI}^{a}$ & $\mathrm{GI}^{b}$ \\
\hline 2 & male & $\mathrm{L}$ & 0.66 & $32 \%$ & $-\mathrm{ve}$ & & $-\mathrm{ve}$ & \\
\hline 9 & male & $\mathrm{L}$ & 0.66 & $40 \%$ & $-\mathrm{ve}$ & & $-\mathrm{ve}$ & \\
\hline 12 & male & $\mathrm{BL}$ & 0.16 & $71 \%$ & $-\mathrm{ve}$ & & & \\
\hline 13 & male & $\mathrm{L}$ & 1.66 & $28 \%$ & 0.83 & $80 \%$ & $-\mathrm{ve}$ & \\
\hline 18 & male & TM & $-\mathrm{ve}$ & & $-v e$ & & $-\mathrm{ve}$ & \\
\hline 20 & male & $\mathrm{L}$ & 0.33 & $82 \%$ & $-\mathrm{ve}$ & & $-\mathrm{ve}$ & \\
\hline 23 & female & $\mathrm{L}$ & 1.16 & $42 \%$ & $-\mathrm{ve}$ & & $-\mathrm{ve}$ & \\
\hline 24 & female & $\mathrm{L}$ & 0.66 & $53 \%$ & $-v e$ & & $-\mathrm{ve}$ & \\
\hline 26 & male & $\mathrm{L}$ & 1.00 & $22 \%$ & 0.83 & $55 \%$ & $-v e$ & \\
\hline 22 & male & $\mathrm{L}$ & $-\mathrm{ve}$ & & $-\mathrm{ve}$ & & & \\
\hline 8 & male & L & 0.83 & $42 \%$ & $\begin{array}{l}1.00 \\
0.33\end{array}$ & $\begin{array}{l}65 \% \\
72 \%\end{array}$ & $\begin{array}{l}\text { OB } \\
\text { OB }\end{array}$ & $\begin{array}{l}98 \% \\
98 \%\end{array}$ \\
\hline 29 & male & $\mathrm{L}$ & 1.00 & $37 \%$ & 0.33 & $72 \%$ & OB & \\
\hline 3 & male & $\mathrm{L}$ & 1.16 & $20 \%$ & 1.00 & $52 \%$ & 0.16 & $98 \%$ \\
\hline 7 & male & $\mathrm{L}$ & 1.16 & $30 \%$ & 0.66 & $60 \%$ & 0.16 & $96 \%$ \\
\hline 10 & male & $\mathrm{L}$ & 1.33 & $12 \%$ & 0.16 & $90 \%$ & 0.16 & $98 \%$ \\
\hline 11 & male & $\mathrm{L}$ & 1.16 & $32 \%$ & 0.66 & $57 \%$ & 0.16 & $97 \%$ \\
\hline 19 & male & $\mathrm{L}$ & 0.16 & $79 \%$ & 1.00 & $50 \%$ & 0.16 & $98 \%$ \\
\hline 4 & male & $\mathrm{BL}$ & 1.00 & $22 \%$ & 0.83 & $37 \%$ & 0.5 & $87 \%$ \\
\hline 6 & male & $\mathrm{L}$ & 1.00 & $37 \%$ & 1.00 & $62 \%$ & 0.5 & $78 \%$ \\
\hline 28 & male & $\mathrm{L}$ & 1.00 & $30 \%$ & 0.66 & $55 \%$ & 0.5 & $82 \%$ \\
\hline 27 & male & $\mathrm{L}$ & 1.00 & $15 \%$ & 1.00 & $56 \%$ & 0.83 & $72 \%$ \\
\hline 1 & male & $\mathrm{L}$ & 1.16 & $10 \%$ & 1.00 & $25 \%$ & 1.00 & $25 \%$ \\
\hline 21 & male & $\mathrm{L}$ & 1.66 & $12 \%$ & 1.16 & $20 \%$ & 1.00 & $38 \%$ \\
\hline 16 & male & $\mathrm{L}$ & 1.00 & $35 \%$ & 1.00 & $67 \%$ & 1.00 & $60 \%$ \\
\hline 17 & male & $\mathrm{L}$ & 1.00 & $20 \%$ & 1.00 & $35 \%$ & & \\
\hline 25 & male & $\mathrm{L}$ & 1.00 & $22 \%$ & 0.83 & $30 \%$ & 1.00 & $27 \%$ \\
\hline 5 & male & $\mathrm{L}$ & 1.33 & $15 \%$ & 1.00 & $35 \%$ & 1.16 & $22 \%$ \\
\hline 14 & male & $\mathrm{L}$ & 2.00 & $11 \%$ & 1.16 & $34 \%$ & 1.5 & $60 \%$ \\
\hline 15 & male & $\mathrm{L}$ & 1.66 & $10 \%$ & 0.66 & $45 \%$ & 1.5 & $60 \%$ \\
\hline
\end{tabular}

${ }^{a} \mathrm{BI}$ : The mean score of the 6 smears taken from:

(1) the lesion, (2) right ear, (3) left ear, (4) forehead (5) right cheek and (6) left cheek, in the Bacterial Index (BI) of the patients.

${ }^{b} \mathrm{GI}$ : The Granularity Index (GI) is divided into 3 groups:

(1) solid, (2) fragmented, (3) granular (SFG).

The mean score of the granular bacilli only found in the 6 smears is given.

The results (BI and GI) are read under the ordinary medical microscope using the oil immersion objective. Smears stained with Ziehl-Neelsen's stain using 10\% sulphuric acid as the decolourizer.

reaction; repeated severe exacerbations leading to precarious condition; ulceration of lepromas, involvement of lymph glands, enlargement with tenderness of liver and spleen; life saving administration of steroids; no specific anti-leprosy treatment tolerated. Patient was steroid dependent which had to be given continuously in varying dosages. At the beginning of the drug combination 
trial with rifampicin and Isoprodian, prednisolone was withdrawn. Only twice was a short course needed during the drug trial period.

Skin smear. Beginning 1.16, after 3 months negative, at present negative. Combined treatment stopped after 12 months (May, 1974). Attack of Malaria ( $P$. vivax and $P$. falciparum) subsided with adequate routine treatment without complications. Now on dapsone $175 \mathrm{mg} /$ week; no re-activation of Myco. leprae.

\section{Patient No. 24}

Name: K., Age: 24 years, female, Type $L^{1}$ (macular lepromatous). Onset of the disease in 1966. Treatment taken at Government Hospital, Salem. Skin biopsy Nos $7 / 74$ and $14 / 74$.

First admission in our Centre in 1968 in a severe condition, with dermatitis exfoliativa and 9 months hospitalization. Thereafter tentative introduction of dapsone treatment which was not tolerated. Patient was in chronic reaction. January, 1972, primary pulmonary tuberculosis of right lung verified. Routine TB treatment with streptomycin, PAS and INH was given. Occasional mild reaction with ENL of short duration. Dapsone orally was introduced again by end of 1972, $50 \mathrm{mg} /$ week. No complications during drug trial period of RMP + Isoprodian. Clinically and radiologically no more pathological findings in the lungs.

Skin smear. Onset 0.66 after 3 months negative, after 1 year negative. Now on dapsone $300 \mathrm{mg} /$ week and follow-up.

\section{Patient No. 13}

Name: K., Age: 40 years, male, Type L (macular lepromatous). Skin biopsy No. $10 / 74$.

Under treatment since 1961, received up to $200 \mathrm{mg} /$ week dapsone, attendance very irregular till 1969. In October 1969, severe reaction occurred with ulceration of the skin lesions and bilateral ulnar neuritis. Reaction controlled with thalidomide. Treatment with "Ciba 1906" (thiambutosine). Repeated recurrence of reactions. No improvement. Combined therapy of rifampicin + Isoprodian was well tolerated. After introductory phase, thalidomide was completely withdrawn and not required again. Clinically much improved-disfiguring scars and hyperpigmentations diminished. Both ulnar nerves quiescent. Follow-upunder further observation.

Skin smear. Onset 1.66, after 3 months 0.83 , after 1 year negative.

Occupation. Coolie, working capacity restored. No specific treatment at present.

\section{Patient No. 29}

Name: M., Age: 24 years, male, Type L. Biopsy No. 8/74.

Suffering from leprosy for the past 15 years. Treatment with us since 1965 . Oral treatment with dapsone was first tolerated up to dosage of $150 \mathrm{mg} /$ week. First admission in February 1965 with severe reaction. After that date follows a history of chronic reaction with severe exacerbations and nerve involvement. Futile attempts of treatment with several recommended anti-leprosy drugs (thiourea, carbazone, INH, Ciba 1906, Fantorin, PAT (Pot. Ammonium 
Tartrate) and since 1970 thalidomide dependent. Steroid-prednisolone, and thalidomide were withdrawn during drug trial period. Short courses of thalidomide were given to control reaction occasionally when required.

Skin smear. Onset 1.00 , after 3 months 0.33 , after 1 year OB (occasional bacilli). Patient now on dapsone $400 \mathrm{mg} /$ week, under further observation and follow-up. 